\title{
Impaired thyrotrophin secretion following the administration of thyrotrophin-releasing hormone in Type II diabetes mellitus
}

\author{
Michael Small, Howard N. Cohen, John A. MacLean, Graham H. Beastall and \\ Angus C. MacCuish
}

Diabetic Unit and Department of Pathological Biochemistry, Royal Infirmary, Glasgow, G4 OSF, Scotland, UK

\begin{abstract}
Summary: Serum thyrotrophin has been measured before and after the intravenous administration of $200 \mu \mathrm{g}$ of thyrotrophin-releasing hormone in 91 white subjects $(33$ stable diabetic patients and 58 healthy controls), none of whom had any clinical evidence of thyroid or pituitary dysfunction. Seven of the diabetic subjects failed to achieve a rise of serum thyrotrophin of $>2 \mathrm{mU} / 1$ above basal concentrations, as compared with only one of the control subjects $(P=0.006)$. The difference in response between diabetics and controls was confined to patients with Type II (non-insulin-dependent) diabetes: thus 5 of 13 Type II patients and 2 of 20 Type I (insulin-dependent) patients failed to show a normal response to thyrotrophin releasing hormone injection. No significant effect of glycaemic control on thyrotrophin responses was noted.

These results suggest that Type II diabetes mellitus may be a cause of impaired thyrotrophin secretion in patients with no clinical evidence of pituitary disease. The mechanism for this impaired pituitary hormone release remains to be clarified.
\end{abstract}

\section{Introduction}

The ability of an intravenous injection of synthetic thyrotrophin releasing hormone (TRH) to stimulate release of thyrotrophin (TSH) from the anterior pituitary is widely recognized as a useful test both to assess the integrity of the hypothalamic-pituitary axis (Jackson, 1982) and to confirm a diagnosis of thyrotoxicosis (Hall et al., 1980; Stitch, 1980). Thus patients with thyrotoxicosis are distinguished by a failure of serum TSH to rise by $>2 \mathrm{mU} / 1$ within 20 minutes of the intravenous injection of $200 \mu \mathrm{g}$ TRH (Hall et al., 1980; Stitch, 1980). There is a strong association between diabetes and thyroid disorders with clinical and subclinical autoimmune thyroid disease common in diabetic populations (Gray \& Clarke, 1978; Feely \& Isles, 1979; Gray et al., 1981). Antibodies to the anterior pituitary gland have been detected in Type I (insulin-dependent) diabetes (Bottazo et al., 1975) and a relationship between poor diabetic control and impaired TSH secretion has been observed in Type II (non-insulin-dependent) diabetes (Kabadi, 1984), and it is possible that dynamic pituitary hormonal responses may be blunted in diabetes. We have therefore measured the TSH response to TRH injection, in patients with both clinical

Correspondence: M. Small, M.B., Ch.B., M.R.C.P., Diabetic Unit, Royal Infirmary, Glasgow, G4 OSF, UK.

Accepted: 13 December 1985 types of diabetes, in an attempt to determine whether subclinical pituitary dysfunction is common in diabetes and whether there is a relationship between TSH secretion and diabetic glycaemic control.

\section{Materials and methods}

Thirty-three diabetic patients and 58 controls were tested; the clinical features are summarized in Table I. The diabetics were all out-patients and non-ketotic and had no previous history or present clinical evidence of thyroid or pituitary disease. The Type II diabetic patients were controlled by diet alone or in combination with an oral sulphonylurea agent. Eight Type II patients had developed secondary failure on sulphonylurea drugs and were being treated with insulin. None of the Type II patients had received any alteration in their therapy in the 3 months prior to their investigation. Eight patients had retinopathy ( 6 background; 2 proliferative). The study design was approved by the local Ethical Committee and informed consent was obtained from the patients.

A cannula was inserted into an ante-cubital fossa vein and 15 minutes later blood was withdrawn for measurement of serum thyroxine (T4), triiodothyronine (T3) and TSH. Prolactin and glycosylated haemoglobin $\left(\mathrm{HbA}_{1}\right)$ were also assayed in the diabetic 
Table I Clinical and biochemical characteristics of the control and diabetic subjects

\begin{tabular}{|c|c|c|c|c|c|c|}
\hline & \multicolumn{2}{|c|}{ Controls } & \multicolumn{4}{|c|}{ Diabetics } \\
\hline & & & \multicolumn{2}{|c|}{ Type I } & \multicolumn{2}{|c|}{ Type II } \\
\hline & Males & Females & Males & Females & Males & Females \\
\hline Number & 28 & 30 & 10 & 10 & 8 & 5 \\
\hline $\begin{array}{l}\text { Age range } \\
\text { (years) }\end{array}$ & $14-65$ & $31-67$ & $15-60$ & $14-64$ & $41-72$ & $55-64$ \\
\hline $\begin{array}{l}\text { Diabetes duration } \\
\text { (years) }\end{array}$ & - & - & $1-39$ & $1-45$ & $1-29$ & $1-16$ \\
\hline $\mathrm{HbA}_{1}(\%)$ & & & $10.9 \pm 2.1$ & $10.7 \pm 2.6$ & $11.4 \pm 1.5$ & $11.6 \pm 1.8$ \\
\hline $\begin{array}{l}\text { TSH non- } \\
\text { responders }\end{array}$ & 1 & 0 & 2 & 0 & 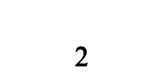 & 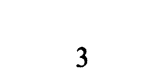 \\
\hline $\begin{array}{l}\text { Prolactin } \\
\text { responses (\%) }\end{array}$ & $60-470$ & $250-1000$ & $412 \pm 293$ & $964 \pm 656$ & $651 \pm 896$ & $675 \pm 300$ \\
\hline
\end{tabular}

Prolactin and $\mathrm{HbA}_{1}$ were not assayed in the control subjects, and the values quoted indicate our laboratory's normal range for these measurements. Values are mean \pm s.d.

patients; $200 \mu \mathrm{g}$ of TRH (Roche Products Ltd) was then injected and blood withdrawn for TSH and prolactin, 30 and 60 minutes after injection. Serum from each patient was stored and assayed for thyroid microsomal and thyroglobulin antibodies if the patient failed to respond to TRH. All the TRH tests were performed between $14.00-16.00 \mathrm{~h}$ in the nonfasting state.

Serum T4, T3 and prolactin were determined by conventional radioimmunoassay. Serum TSH was measured with a two-site immunoradiometric assay based on two different polyclonal antisera, and standardized against MRC 68/38. The TSH assay performed with a mean interassay precision of $>10 \% \mathrm{CV}$ and its sensitivity was $0.5 \mathrm{mU} / 1$. Patients whose TSH concentrations were below the sensitivity of the assay were assigned a value of $0.1 \mathrm{mU} / 1$ for computational purposes. $\mathrm{HbA}_{1}$ was measured by agar gel electrophoresis (Glytrac, Corning). The total integrated TSH concentrations during the 60 minute period following TRH injection were estimated by the trapezoidal rule (Thomas \& Finney, 1979). The area under the curve $(\theta \mathrm{TSH})$ was expressed as mU.h. $1^{-1}$. Statistical analysis utilized Fisher's exact probability test, the Wilcoxon rank sum test and Spearman's rank order correlation coefficient.

\section{Results}

Serum T4, T3, basal TSH and prolactin concentrations were within our normal laboratory reference ranges in all 91 subjects. During the TRH tests only 1 of 58 controls failed to achieve an incremental rise $(\Delta)$ of TSH above pre-injection concentration of $>2 \mathrm{mU} / 1$ (Table I) while 7 of the 33 diabetics also failed to respond $(P=0.006)$. When the diabetic patients were divided into Type I and Type II, only Type II patients showed a statistically significant failure to respond compared to the controls: thus 5 of $13(P=0.001)$ showed inadequate TSH responses while 2 of 20 Type I patients failed to respond $(P=0.29)$. The actual ? responses of TSH are shown in Figure 1. At 30 minutes following TRH the Type II diabetics had significantly lower $(P<0.05)$ TSH concentrations (mean \pm s.d. $6.0 \pm 5.8)$ compared with the controls $(9.7 \pm 5.5)$. Table II shows the $\Delta$ TSH and $\theta$ TSH in controls and diabetic patients. This shows the similarity of response of TSH in controls and Type I patients but a significantly impaired response in the Type II subjects. While the basal TSH concentrations, $\triangle$ TSH and $\theta$ TSH were slightly greater in females, there were no significant differences in these TSH values between the sexes in either controls or patients. No association with retinopathy was noted: 3 of the 7 TSH nonresponders had retinopathy while 4 of 26 responders had retinopathy $(P=0.25)$. Of the subjects who failed to demonstrate a TSH response only one Type I male patient had thyroid microsomal antibodies detectable in a titre of $1 / 1600$.

Overall we found no significant correlation of $\mathrm{HbA}_{1}$ with either $\Delta$ TSH $(r=0.01)$ or $\theta$ TSH $(r=0.09)$. When the diabetics were divided by sex or type of diabetes no significant correlations with glycaemic control were found. In males, significant correlations were noted between age and both $\Delta$ TSH $(r=-0.59$, $P<0.02)$ and $\theta$ TSH $(r=-0.55, P<0.05)$, while no such associations were noted in females $(r=-0.22$; 


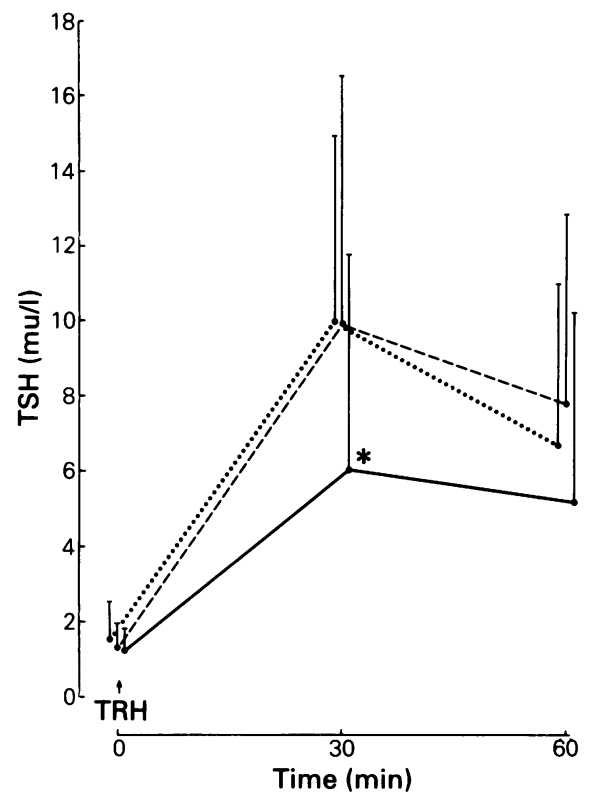

Figure 1 Serum TSH time following i.v. administration of $200 \mu \mathrm{g}$ TRH in 58 control patients (.....), 20 Type 1 diabetics (-- --$)$ and 13 Type II diabetic patients (${ }^{*} P<0.05$ (compared to control patients).

$r=-0.33$ respectively). No significant correlations were noted between $\Delta \mathrm{TSH}$ and serum $\mathrm{T} 3, \mathrm{~T} 4$ or duration of diabetes.

Diabetic patients showed a normal prolactin response to TRH and no correlation of prolactin response and $\mathrm{HbA}_{1}$ was noted. The slightly greater response in Type II male patients (Table I) was caused by an exaggerated prolactin response in a single subject. A prolactin response was seen in all patients indicating that the TRH had been injected and was exerting its expected metabolic effect.

\section{Discussion}

TSH secretion following TRH administration was impaired in $38 \%$ of our Type II diabetic patients compared with only $1.7 \%$ of controls. This finding is of clinical importance since thyrotoxicosis is as common in Type II as in Type I patients in a diabetic clinic (Gray et al., 1981) and a false diagnosis of thyrotoxicosis could be made in Type II diabetic patients on the basis of impaired TSH secretion. We excluded patients
Table II TSH responses in the control and diabetic subjects

\begin{tabular}{lll}
\hline & $\begin{array}{c}\Delta T S H \\
(\mathrm{mU} / \mathrm{l})\end{array}$ & $\begin{array}{c}\theta T S H \\
\left(\mathrm{mU} . \mathrm{h}^{-1}\right)\end{array}$ \\
\hline Controls & $8.2 \pm 4.8$ & $417 \pm 239$ \\
Type I & $8.3 \pm 5.1$ & $431 \pm 281$ \\
Type II & $5.1 \pm 5.5^{*}$ & $269 \pm 261^{*}$ \\
\hline
\end{tabular}

Shows the incremental rise $(\Delta)$ and area under the TSH curve $(\theta)$ in both diabetics and controls; ${ }^{*} P<0.05$ (compared to controls): values are mean \pm s.d.

with other recognized causes of impaired TRH evoked TSH secretion such as hypopituitarism, acromegaly, ophthalmic Grave's disease, autonomous thyroid nodule, multinodular goitre, and certain drugs (Hall et al., 1980; Stitch, 1980). Thyroid autoimmunity is no more common in Type II diabetic patients than in a matched control group (Kasim \& Bessman, 1984) and it seems unlikely that the depressed TSH secretion could have an autoimmune basis. Earlier workers (Ormiston et al., 1971), as in the present study, have reported impaired TSH release in an occasional normal subject and the reasons for this are not known.

Kabadi (1984) has shown a negative association of $\mathrm{HbA}_{1 \mathrm{C}}$ levels and TSH responses in males with Type II diabetics and that the impaired TSH responses could be normalized on improvement of glycaemic control. We have not found such an association and our study suggests that factors other than poor glycaemic control must be important: some of our patients with Type I diabetes were also poorly controlled, as judged by their high mean $\mathrm{HbA}_{1}$ concentrations, yet they had normal TSH (and prolactin) responses. Others have noted normal TSH responses in Type I diabetes (Morley et al., 1978; Harrower, 1980; Leroith et al., 1980; Dasmahapatra et al., 1981; MacFarlane et al., 1982; Salardi et al., 1984) and that improvement of glycaemic control did not alter the TSH responses to TRH (MacFarlane et al., 1982). Despite the occasional presence of antibodies to anterior pituitary cells in Type I diabetes (Bottazzo et al., 1975), dynamic biochemical alterations in thyrotroph and lactotroph function do not seem to occur.

In conclusion we feel that Type II diabetes mellitus should be added to the present list of conditions in which diminished TRH evoked TSH secretion may occur. 


\section{References}

BOTTAZZO, G.F., POUPLARD, A., FLORIN-CHRISTENSEN, A. \& DONIACH, D. (1975). Autoantibodies to prolactinsecreting cells of human pituitary. Lancet, ii, 97.

DASMAHAPATRA, A., URDANIVIA, E. \& COHEN, M.P. (1981). Growth hormone response to thyrotrophin-releasing hormone in diabetes. Journal of Clinical Endocrinology and Metabolism, 55, 859.

FEELY, J. \& ISLES, T.E. (1979). Screening for thyroid dysfunction in diabetes. British Medical Journal, 2, 1678

GRAY, R.S. \& CLARKE, B.F. (1978). Primary autoimmune diabetes mellitus. British Medical Journal, 2, 1715.

GRAY, R.S., HERD, R. \& CLARKE, B.F. (1981). The clinical features of diabetes with coexisting autoimmune thyroid disease. Diabetologia, 20, 602.

HALL, R., ANDERSON, J., SMART, G.A. \& BESSER, M. (1980). In Fundamentals of Clinical Endocrinology, 3rd edn. Pitman Medical, The Pitman Press: Bath.

HARROWER, A.D.B. (1980). Growth hormone, prolactin and thyrotrophin responses to thyrotrophin-releasing hormone in diabetic patients. Postgraduate Medical Journal, 56, 481 .

JACKSON, I.M.D. (1982). Thyrotrophin-releasing hormone. New England Journal of Medicine, 306, 145.

KABADI, U.M. (1984). Impaired thyrotroph function in uncontrolled Type II diabetes mellitus: normalization on recovery. Journal of Clinical Endocrinology and Metabolism, 59, 521.

KASIM, S. \& BESSMAN, A. (1984). Thyroid autoimmunity in Type 2 (non-insulin-dependent) diabetic patients of
Caucasian, Black and Mexican origin. Diabetologia, 27, 59.

LEROITH, D., SHAPIRO, M., LUBOSHITSKY, R. \& SPITZ, I.M. (1980). The hypothalmic-pituitary axis in diabetes mellitus. Hormone and Metabolic Research, 12, 608.

MACFARLANE, I.A., SHEPPARD, M.C., GILBEY, S., BLACK, E.G. \& WRIGHT, A.D. (1982). Thyroid stimulating hormone secretion in Type I (insulin-dependent) diabetic patients: influence of metabolic control. Diabetologia, 23, 471 (abstract).

MORLEY, J.E., KLEIN, C., KALK, W.J., JOFFE, B.I., SAFFER, D., DISTILLER, L.A. \& SEFTEL, H.C. (1978). Pituitary responsiveness to thyrotrophin releasing hormone in insulin-dependent diabetes mellitus. Hormone and Metabolic Research, 10, 231.

ORMISTON, B.J., GARRY, R., CRYER, R.J., BESSER, G.M. \& HALL, R. (1971). Thyrotrophin-releasing hormone as a thyroid-function test. Lancet, ii, 10.

SALARDI, S., FAVA, A., CASSIO, A., CICOGNANI, A., TASSONI, P., PIRAZZOLI, P., FREJAVILLE, E., BALSAMO, A., COZZUTI, E. \& CACCIARI, E. (1984). Thyroid function and prolactin levels in insulin-dependent diabetic children and adolescents. Diabetes, 33, 522.

STITCH, S.R. (1980). In Specialized Assay Services for Hospital Laboratories, 3rd edn. Leeds University Press: Leeds.

THOMAS, G.B. \& FINNEY, R.L. (1979). In Calculus and Analytic Geometry, 5th edn. Addison-Wesley: Reading. 